\title{
Report of a de novo c.2605C > T (p.Pro869Ser) change in the MED13L gene and review of the literature for MED13L- related intellectual disability
}

Zhi Yi ${ }^{1}$, Ying Zhang ${ }^{1}$, Zhenfeng Song ${ }^{1}$, Hong Pan ${ }^{2}$, Chengqing Yang ${ }^{1}$, Fei Li ${ }^{1}$, Jiao Xue ${ }^{1}$ and Zhenghai Qu ${ }^{1 *}$ (D)

\begin{abstract}
Background: MED13L-related intellectual disability is a new syndrome that is characterized by intellectual disability (ID), motor developmental delay, speech impairment, hypotonia and facial dysmorphism. Both the MED13L haploinsufficiency mutation and missense mutation were reported to be causative. It has also been reported that patients carrying missense mutations have more frequent epilepsy and show a more severe phenotype.

Case presentation: We report a child with ID, speech impairment, severe motor developmental delay, facial deformity, hypotonia, muscular atrophy, scoliosis, odontoprisis, abnormal electroencephalogram (EEG), and congenital ureteropelvic junction obstruction (UPJO) combined with high ureter attachment. We used wholeexome sequencing (WES) to detect the genetic aberration of the child and found a de novo mutation, c.2605C > T (p.Pro869Ser), in the MED13L gene. Neither of her parents carried the mutation. Additionally, we review the literature and summarize the phenotypes and features of reported missense mutations. After reviewing the literature, approximately 17 missense mutations in 20 patients have been reported thus far. For 18 patients (including our case) whose clinical manifestations were provided, $100 \%$ of the patients had ID or developmental delay (DD). A total of 88.9, 83.3 and $66.7 \%$ of the patients had speech impairment, delayed milestones and hypotonia, respectively. A total of $83.3 \%$ of the patients exhibited craniofacial deformity or other dysmorphic features. Behavioral difficulties and autistic features were observed in $55.6 \%$ of the patients. Cardiac anomalies were seen in only $27.8 \%$ of the patients. Of these patients, $44.4 \%$ had epileptic seizures. Of the 17 mutations, 2 were located in the $\mathrm{N}$-terminal domain, 8 were located in the C-terminal domain, and 1 was located in an a-helical sequence stretch. One of them was located in the MID domain of the MedPIWI module.
\end{abstract}

Conclusions: We report a new patient with a reported missense mutation, c.2605C > T (p.Pro869Ser), who exhibited some infrequent manifestations except common phenotypes, which may broaden the known clinical spectrum. Additionally, by reviewing the literature, we also found that patients with missense mutations have a higher incidence of seizures, MRI abnormalities, autistic features and cardiac anomalies. They also have more severe ID and hypotonia. Our case further demonstrates that Pro869Ser is a hotspot mutation of the MED13L gene.

Keywords: MED13L, Missense mutation, Intellectual disability, Speech impairment

\footnotetext{
*Correspondence: quzhenghai@163.com

'Department of Pediatric, The Affiliated Hospital of Qingdao University, Qingdao 266003, Shandong, China

Full list of author information is available at the end of the article
}

(c) The Author(s). 2020 Open Access This article is licensed under a Creative Commons Attribution 4.0 International License, which permits use, sharing, adaptation, distribution and reproduction in any medium or format, as long as you give appropriate credit to the original author(s) and the source, provide a link to the Creative Commons licence, and indicate if changes were made. The images or other third party material in this article are included in the article's Creative Commons licence, unless indicated otherwise in a credit line to the material. If material is not included in the article's Creative Commons licence and your intended use is not permitted by statutory regulation or exceeds the permitted use, you will need to obtain permission directly from the copyright holder. To view a copy of this licence, visit http://creativecommons.org/licenses/by/4.0/. The Creative Commons Public Domain Dedication waiver (http://creativecommons.org/publicdomain/zero/1.0/) applies to the data made available in this article, unless otherwise stated in a credit line to the data. 


\section{Background}

Mediator complex subunit 13-like gene (MED13L), which is a component of the Mediator complex in HeLa cells [1], was first linked to intellectual disability (ID) and congenital heart disease (CHD) in 2003 by Muncke et al. [2]. The patient reported by Muncke et al. harbored a translocation disrupting $M E D 13 L$, and three additional missense mutations in MED13L (p.Glu251Gly, p.Arg1872His, and p.Asp2023Gly) were found by mutation screening of dextro-looped transposition of the great arteries (dTGA) patients. Muncke et al. cloned MED13L using a positional cloning approach, and they designated the gene as PROSIT240 due to the protein similarity to the human thyroid hormone receptorassociated protein 240 [2]. Independently, Musante et al. cloned the gene by RT-PCR and 5-prime RACE of human fetal brain and lymphoblastoid cell line cDNA libraries, which they called THRAP2 [3]. A decade later, an increasing number of cases harboring large intragenic or whole gene deletions/duplications of the MED13L gene, chromosomal translocation disrupting the $M E D 13 L$ gene, de novo frameshift variants, nonsense mutations, and splice site mutations were published, exhibiting moderate ID, severe speech impairment, motor developmental delay, facial deformity and/or $\mathrm{CHD}$, and these were recognized as MED13L haploinsufficiency syndrome [4-11]. Several missense mutations in the MED13L gene have also been reported and are supposed to frequently have a more severe phenotype with hypotonia, more frequently epilepsy, severe absent speech, and severely delayed motor function compared to patients with truncating variants [11-14].

Here, we report another de novo p.Pro869Ser change in the MED13L gene that exhibits ID, speech impairment, severe motor developmental delay, facial deformity, hypotonia, muscular atrophy, hyperlaxity of the joints, scoliosis, odontoprisis, abnormal electroencephalogram (EEG), and congenital ureteropelvic junction obstruction (UPJO) combined with high ureter attachment that has never been reported in $M E D 13 L$-related syndrome. Our observation of UPJO in this patient further broadens the known clinical spectrum. Additionally, we review the current literature to summarize in detail the missense mutations of the MED13L gene and the clinical characteristics of reported patients with missense mutations of the MED13L gene.

\section{Case presentation and methods Case presentation}

The patient is a girl who was born at term after 38 weeks of pregnancy with a birth weight of $2500 \mathrm{~g}$, without a history of asphyxia at birth. She is one of a fraternal pair of twins as the second pregnancy of healthy, nonconsanguineous parents. Her older sister and twin brother are healthy. She is 4 years and 5 months old now, weighs $11 \mathrm{~kg}(<\mathrm{P} 3)$ and is $100 \mathrm{~cm}$ tall (between P3 and P10). Her head circumference was $45 \mathrm{~cm}(<\mathrm{P} 3)$. She had hypotonia since birth and presented muscular atrophy of the extremities as well as hyperlaxity of the joints. She had scoliosis and had spontaneous fracture of the distal right femur at 1 year old. Abnormal facial deformity includes frontal bossing, low-set ears, hypertelorism, epicanthus, depressed nasal bridge, bulbous nasal tip, cupid-bow upper lip combined with open mouth appearance and micrognathia (Fig. 1). From 3 years and 4 months old, she had unconscious frequent odontoprisis. Her developmental milestones were severely delayed, as she raised her head at 1 year. At the last evaluation, the girl was 4 years and 5 months old, and she could not yet sit or stand without support, let alone walk. Her speech was also severely delayed; she can speak single words such as "Ma, Pa" with ambiguous pronunciation, and she can understand simple instructions. She also exhibits autistic features. She had no clinically observed seizures but had abnormal EEG showing spike and slow wave colligation and multi-spike and slow waves in the bilateral occipital and posterior temporal regions, as well as rapid rhythm distribution in the occipital area (Fig. 2). Magnetic Resonance Imaging (MRI) at 5 months old showed enlarged bilateral lateral ventricles. Echocardiography found patent ductus arteriosus that was closed at 2 years and 10 months, and mild aortic coarctation, mild aortic regurgitation and slight tricuspid regurgitation

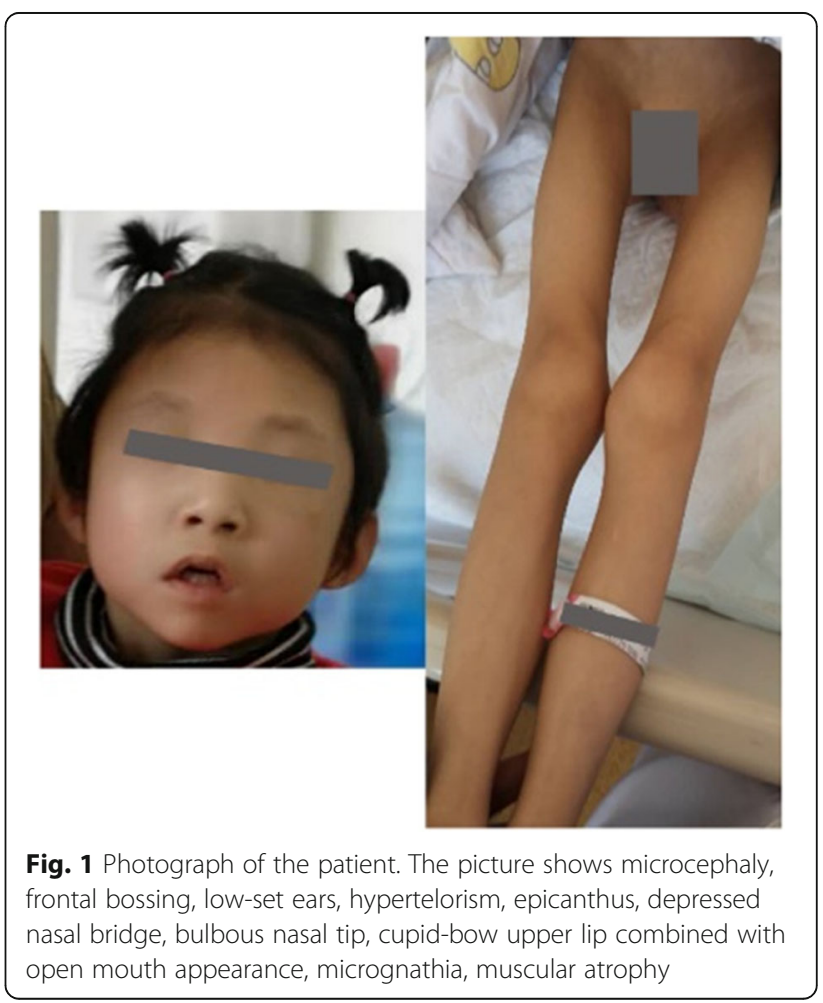




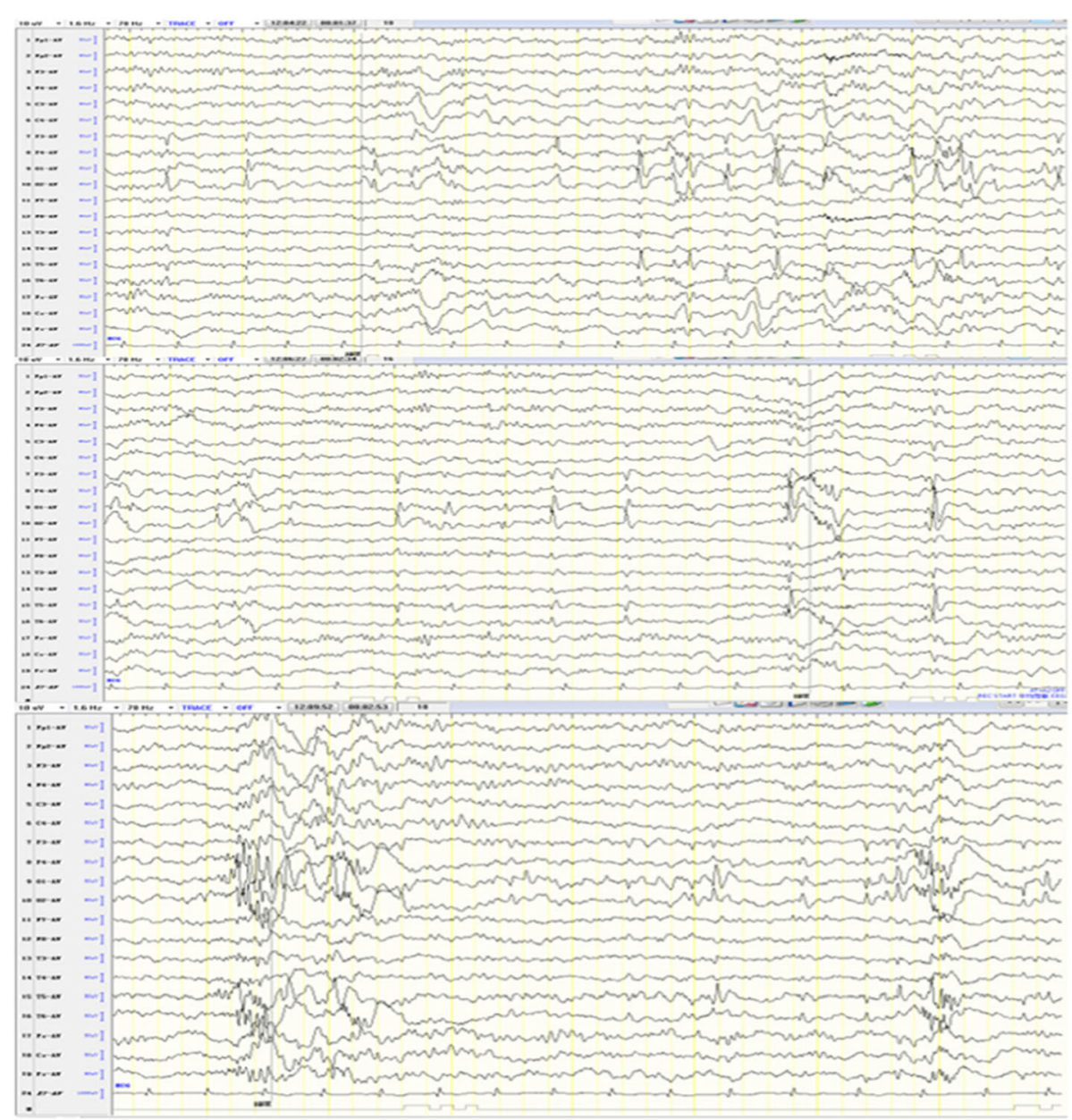

Fig. 2 EEG shows spike and slow wave colligation and multi-spike and slow waves in the bilateral occipital and posterior temporal regions, as well as rapid rhythm distribution in the occipital area

appeared. UPJO combined with high ureter attachment of the right was discovered in this girl due to uronephrosis, and she underwent surgery at 6 months old. Now she still has a mild right kidney seeper.

Whole-exome sequencing (WES) found a de novo mutation, c.2605C > T (p.Pro869Ser), in the MED13L gene. Neither of her parents had the mutation. The region of the mutation is an important part of the protein, with highly conserved amino acid sequences in different species. This mutation is predicted to be disease causing by Mutation Taster (http://www.mutationtaster.org/) and is predicted to be damaging with a score of 1.000 (sensitivity: 0.00; specificity: 1.00) by Polyphen 2 (http://genetics. bwh.harvard.edu/pph2/) and damaging with a score of 0.000 by SIFT (cutoff $=0.05$ ) (http://sift.jcvi.org/www/ SIFT_BLink_submit.html).

By reviewing the literature, approximately 17 missense mutations in 20 patients have been reported thus far. Together with our case, a total of 21 patients with MEDL13L missense mutations are summarized in Table 1. Among them, 18 patients (including our case) were provided with clinical manifestations. One hundred percent of the patients have ID or DD. A total of $88.9,83.3$ and $66.7 \%$ of the patients had speech impairment, delayed milestones and hypotonia, respectively. A total of $83.3 \%$ of the patients exhibited craniofacial deformity or other dysmorphic features, and the most common features were low-set ears, hypertelorism, depressed nasal bridge, bulbous nasal tip, cupid-bow upper lip and open mouth appearance. Behavioral difficulties, such as self-harm and autistic features, were seen in $55.6 \%$ of the patients. Cardiac anomalies are seen in only $27.8 \%$ of the patients, and there is no complex CHD. Of the patients with missense mutations, $44.4 \%$ have epileptic seizures, and even one patient with c.2579A $>$ G(Asp860Gly) has intractable seizures. In 12 patients who received MRI examination, 8 (66.7\%) had abnormalities, and most of these anomalies were nonspecific. Of the 17 mutations, 2 were located in the $\mathrm{N}$-terminal domain, 8 were located in the $\mathrm{C}$-terminal domain, and 1 was located in an $\alpha$-helical sequence 


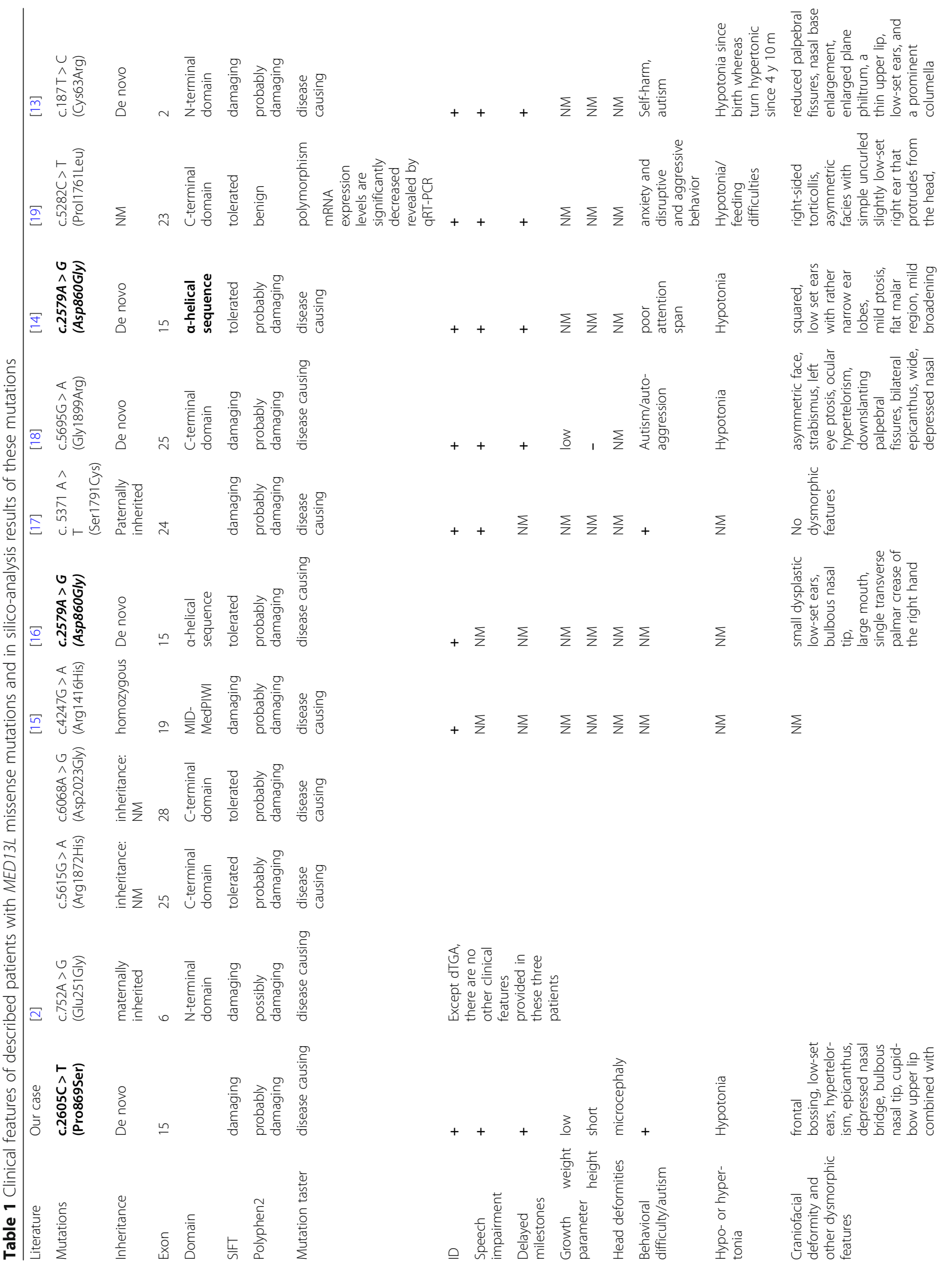




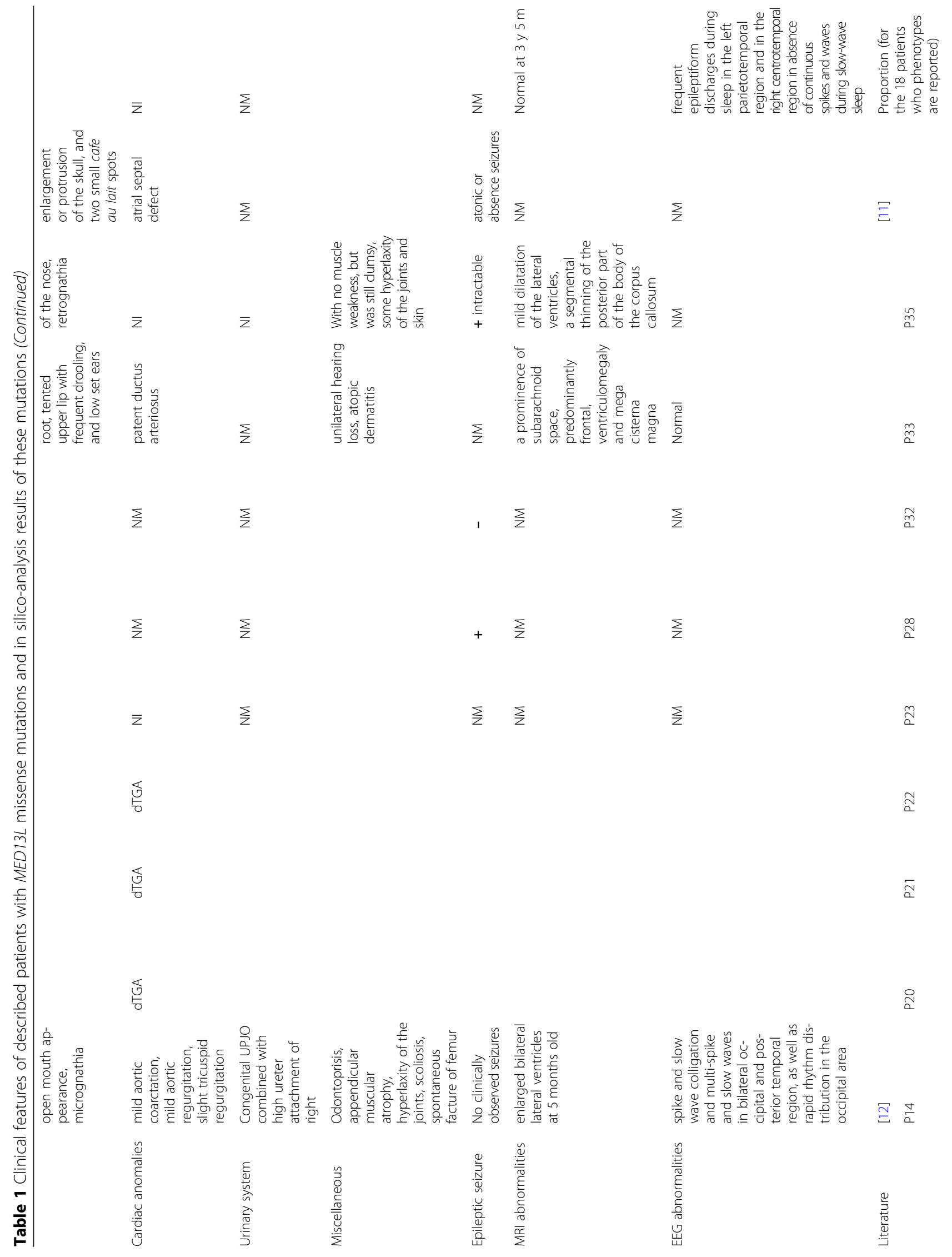




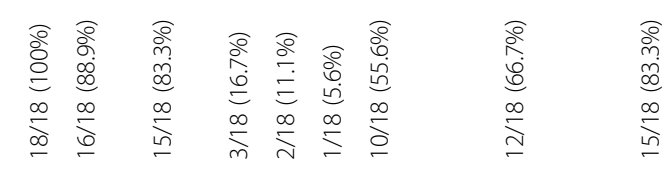

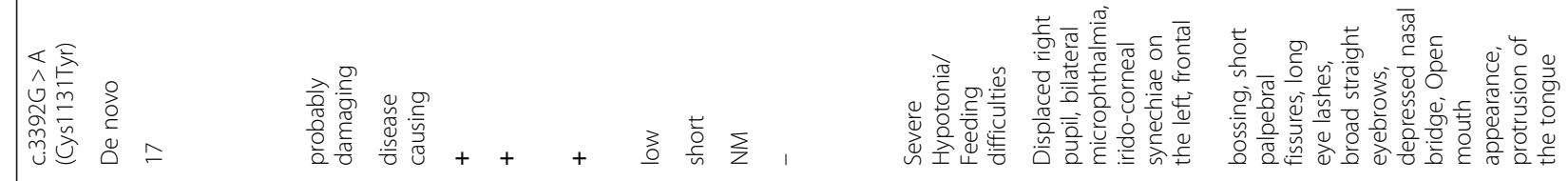
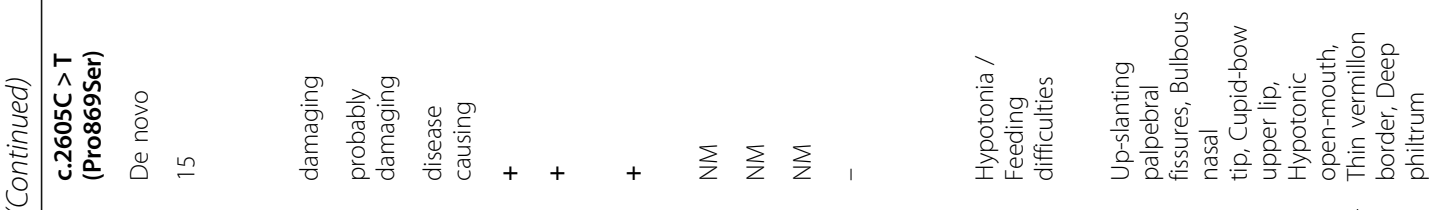

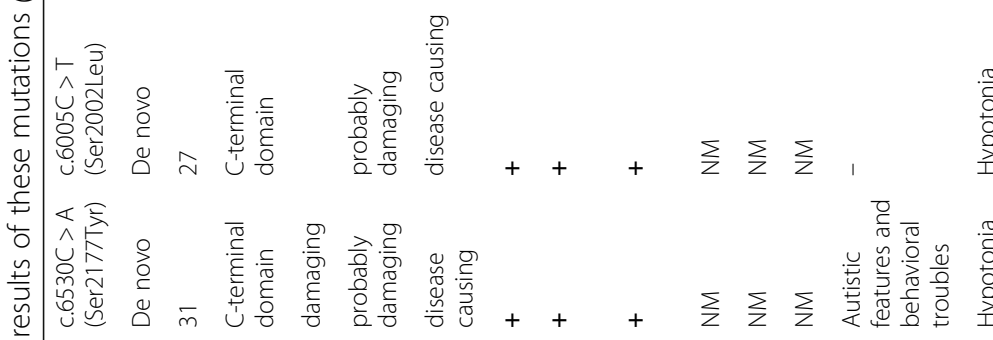

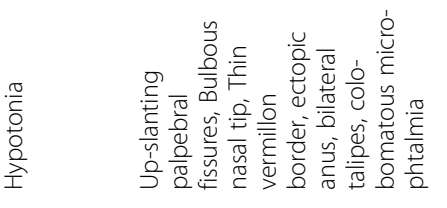

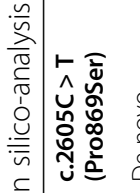

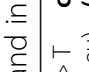
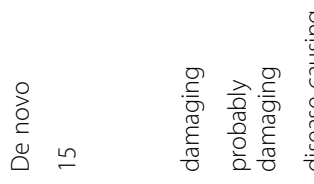

\section{$\frac{\sqrt[0]{\frac{1}{n}}}{\cos }$}




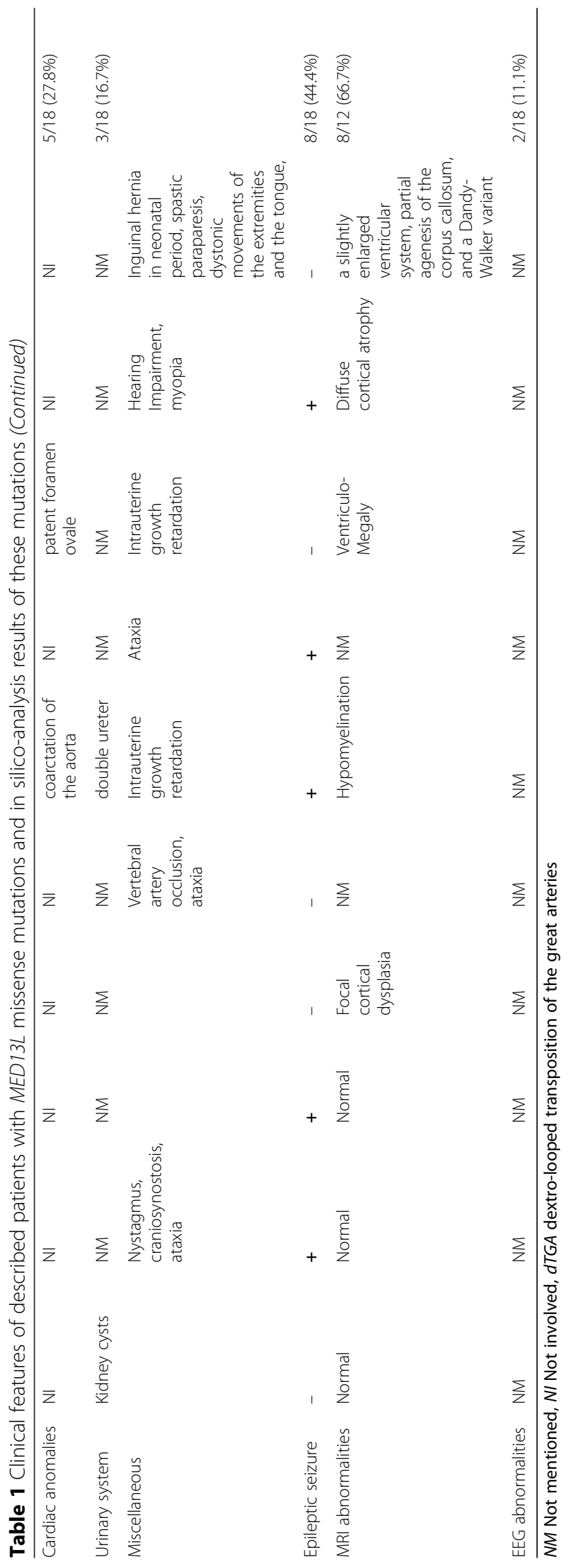


stretch spanning residues Val858-Met864 [14]. Another mutation, Arg1416His, was located in the MID domain of the MedPIWI module (http://pfam.xfam.org/).

\section{Methods}

\section{Target capture and sequencing}

After obtaining informed consent from her parents, peripheral blood of the proband and her parents was sent to Guangzhou Jiajian Medical Testing Co., Ltd. Genomic DNA was extracted from peripheral blood using the Solpure Blood DNA Kit (Magen) according to the manufacturer's instructions. The genomic DNA of the proband and her parents was then fragmented by the Q800R Sonicator (Qsonica) to generate $300-500$ bp insert fragments. The paired-end libraries were prepared following the Illumina library preparation protocol. Customdesigned NimbleGen SeqCap probes (Roche NimbleGen, Madison, Wis) were used for in-solution hybridization to enrich target sequences. Enriched DNA samples were indexed and sequenced on a NextSeq500 sequencer (Illumina, San Diego, Calif) with 100,150 cycles of single end reads, according to the manufacturer's protocols.

\section{Variant annotation and interpretation}

Primary data came in fastq form after image analysis, and base calling was conducted using the Illumina Pipeline. The data were filtered to generate 'clean reads' by removing adaptors and low-quality reads (Q20). Sequencing reads were mapped to the reference human genome version hg19 (2009-02 release, http://genome.ucsc.edu/). Nucleotide changes observed in aligned reads were called and reviewed by using NextGENe software (SoftGenetics, State College, Pa). In addition to the detection of deleterious mutations and novel single nucleotide variants, a coverage-based algorithm developed in-house, eCNVscan, was used to detect large exonic deletions and duplications. The normalized coverage depth of each exon of a test sample was compared with the mean coverage of the same exon in the reference file to detect copy number variants (CNVs). Sequence variants were annotated using population and literature databases including 1000 Genomes, dbSNP, GnomAD, Clinvar, HGMD and OMIM. Some online software programs were used to analyze the structure of the protein, predict the conservation domain and function domain and perform the multiple sequence alignment. Variant interpretation was performed according to the American College of Medical Genetics (ACMG) guidelines [20]. GnomAD, http://gnomad.broadinstitute.org/; Clinvar, https://www. ncbi.nlm.nih.gov/clinvar/; Online Mendelian Inheritance in Man (OMIM) http://omim.org/; 1000 Genomes, http://www.1000genomes.org/.

\section{Review of the literature}

We searched PubMed and identified 10 papers describing individuals with MED13L missense mutations. Seventeen missense mutations have been reported to date.

\section{Discussion and conclusion}

In this study, we report a new patient with a previously reported missense mutation but with some new clinical manifestations. In addition to ID, speech impairment, motor developmental delay and hypotonia, she also exhibits congenital UPJO combined with high ureter attachment on the right, odontoprisis, appendicular muscular atrophy, scoliosis, and spontaneous facture of femur. Until 4 y $5 \mathrm{~m}$, she had no clinically observed seizures, but EEG revealed spike and slow wave colligation and multi-spike and slow waves in the bilateral occipital and posterior temporal regions, as well as rapid rhythm distribution in the occipital area. However, it is not known whether epilepsy will occur in the future. The two patients P28 and P35 reported by Smol et al. with the same mutation as our case both had seizures, but the ages at first examination were $12 \mathrm{y}$ and $24 \mathrm{y}$, respectively. Therefore, seizures were not observed, which may be due to the limited follow-up time. P28 did not exhibit hypotonia, but P35 and our patient have severe hypotonia. Whereas our patient exhibits autistic features, both P28 and P35 have no autism or behavioral difficulty [12]. Three patients with the same mutation did not have exactly the same clinical manifestations, demonstrating the clinical heterogeneity of patients with MED13L missense mutations. Additionally, urinary system abnormality was not a common manifestation in patients with $M E D 13 L$ missense mutations. However, our case had congenital UPJO, P28 with the same mutation as our case reported by Smol et al. had a double ureter, and another patient with the Thr2162Met mutation by Smol et al. had kidney cysts. Whether urinary system abnormalities are included in the clinical spectrum and how MED13L works in the process of urinary system development require further study. Other infrequent manifestations in our patient, such as odontoprisis, muscular atrophy, spontaneous fracture and scoliosis, also need more case analysis to define whether they are solely caused by MED13L mutations.

By reviewing the literature, we found 17 missense mutations in 20 patients $[2,11-19]$. Compared with the overall incidence in all MED13L-related patients summarized by Torring et al. and Smol et al., patients with missense mutations have a higher incidence of seizures (44.4\% vs $16 \%)$, MRI abnormalities (66.7\% vs $45 \%$ ) and autistic features $(55.6 \%$ vs $23 \%)$ [11, 12]. The incidence of ID and hypotonia was similar to the overall incidence, but the phenotypes were much more serious. The 


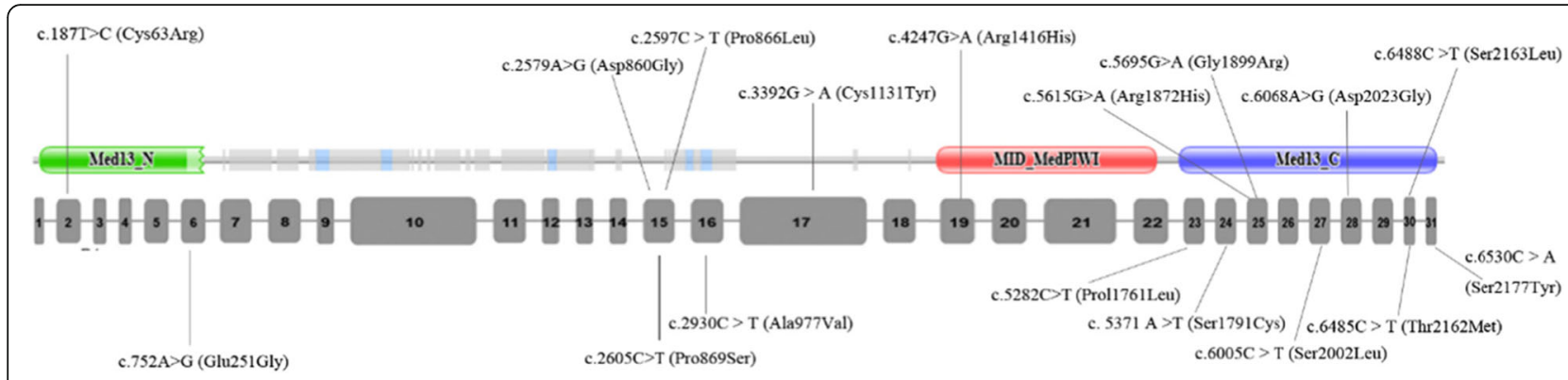

Fig. 3 The locations of the reported 17 missense mutations. Most of them located in exon 15-31. 2 (11.8\%) were located in the N-terminal domain, 8 (47\%) were located in the highly conserved C-terminal domain, 1 of them (Asp860Gly) was located in an a-helical sequence stretch spanning residues Val858-Met864, Another mutation, Arg1416His, was located in the MID domain of the MedPIWI module. MedPIWI is the core globular domain of the Med13 protein

incidence of cardiac anomalies was slightly higher than the overall incidence $(27.8 \%$ vs $19 \%)$ [11].

Of the 17 mutations, $2(11.8 \%)$ were located in the $\mathrm{N}$ terminal domain, 8 (47\%) were located in the highly conserved C-terminal domain, 1 of them (Asp860Gly) was located in an $\alpha$-helical sequence stretch spanning residues Val858-Met864, and replacement of Asp860 by a flexible glycine decreased the helix stability, thereby affecting the secondary structure of MED13L [14]. Another mutation, Arg1416His, was located in the MID domain of the MedPIWI module. MedPIWI is the core globular domain of the Med13 protein. Med13 is a member of the CDK8 subcomplex of the Mediator transcriptional coactivator complex. The MedPIWI module in Med13 is predicted to bind double-stranded nucleic acids, triggering the experimentally observed conformational switch in the CDK8 subcomplex, which regulates the Mediator complex (Fig. 3). By analysis with SIFT, Polyphen 2 and Mutation Taster, all the mutations except Prol1761Leu were predicted to be pathogenic by at least two of the prediction software programs. The mutation Prol1761Leu was predicted to be tolerated, benign, and polymorphic by SIFT, Polyphen 2 and Mutation Taster, respectively. However, the mRNA expression levels of $M E D 13 \mathrm{~L}$ are significantly decreased, as revealed by quantitative RT-PCR, and are supposed to be pathogenic [19]. Therefore, in regard to a missense mutation that was predicted to be benign by software, while the clinical manifestations are highly coincident with MED13L-related disorder, researchers or clinicians should carry out further functional experiments to define the pathogenicity of the mutation.

In this paper, we describe a new patient with $M E D 13 L$ missense mutation who exhibited some infrequent manifestations except common phenotypes, which may broaden the known clinical spectrum. Additionally, we review the literature to summarize patients' phenotypes and features of all reported missense mutations. We also found that patients with missense mutations have a higher incidence of seizures, MRI abnormalities, autistic features and cardiac anomalies. They also have more severe ID and hypotonia, which is consistent with the literature [12]. We need more functional experiments to demonstrate why patients carrying missense mutations have more severe phenotypes. Our case further demonstrates that Pro869Ser is a hotspot mutation of the $M E D 13 L$ gene.

\section{Abbreviations \\ ID: Intellectual disability; DD: Developmental delay; CHD: Congenital heart disease; WES: Whole-exome sequencing; CNV: Copy number variants; UPJO: Ureteropelvic junction obstruction; EEG: Electroencephalogram; MRI: Magnetic resonance imaging; ACMG: American College of Medical Genetics}

\section{Acknowledgments}

We thank the patient and her parents for kind cooperation

\section{Authors' contributions}

Zhi Yi: Conceptualization, Investigation, Validation, Writing-Original Draft; Ying Zhang: Conceptualization, Data Curation; Zhenfeng Song: Formal analysis; Hong Pan: Writing-Review \& Editing; Chengqing Yang: Validation; Fei Li: Investigation; Jiao Xue: Visualization; Zhenghai Qu: Supervision, Resources, Project administration. All authors critically reviewed the manuscript, participated in its revision and approved the final manuscript.

\section{Funding}

No funding has been received from any person or organization for any purpose of this study.

\section{Availability of data and materials}

The datasets generated and analyzed during the current study are all shown in the manuscript

\section{Ethics approval and consent to participate}

Study approval and ethical clearance was obtained from the affiliated hospital of Qingdao university. Written consent was obtained from the guardian of the child prior to data collection.

\section{Consent for publication}

We obtained the written consent for publication from the guardian of the patient.

Competing interests

All authors declare that they do not have any conflict of interest. 


\section{Author details}

'Department of Pediatric, The Affiliated Hospital of Qingdao University, Qingdao 266003, Shandong, China. ${ }^{2}$ Department of Central Laboratory, Peking University First Hospital, Beijing, China.

Received: 18 March 2020 Accepted: 8 June 2020

Published online: 09 July 2020

\section{References}

1. Sato S, Tomomori-Sato C, Parmely TJ, Florens L, Zybailov B, Swanson SK, et al. A set of consensus mammalian mediator subunits identified by multidimensional protein identification technology. Mol Cell. 2004;14:68591. https://doi.org/10.1016/j.molcel.2004.05.006.

2. Muncke $N$, Jung $C$, Rudiger $H$, Ulmer $H$, Roeth $R$, Hubert $A$, et al. Missense mutations and gene interruption in PROSIT240, a novel TRAP240-like gene, in patients with congenital heart defect (transposition of the great arteries). Circulation. 2003;108:2843-50. https://doi.org/10.1161/01.cir.0000103684. 77636.cd.

3. Musante L, Bartsch O, Ropers HH, Kalscheuer VM. cDNA cloning and characterization of the human THRAP2 gene which maps to chromosome 12q24, and its mouse ortholog Thrap2. Gene. 2004;332:119-27. https://doi. org/10.1016/j.gene.2004.02.044.

4. Asadollahi R, Oneda B, Sheth F, Azzarello-Burri S, Baldinger R, Joset P, et al. Dosage changes of MED13L further delineate its role in congenital heart defects and intellectual disability. Eur J Hum Genet. 2013;21:1100-4. https:// doi.org/10.1038/ejhg.2013.17.

5. Doco-Fenzy M, Genevieve D, Sarda P, Edery P, Isidor B, Jost B, et al. Impaired development of neural-crest cell-derived organs and intellectual disability caused by MED13L haploinsufficiency. J Med Genet. 2014;35:131120. https://doi.org/10.1002/humu.22636.

6. Adegbola A, Musante L, Callewaert B, Maciel P, Hu H, Isidor B, et al. Redefining the MED13L syndrome. Eur J Hum Genet. 2015;23:1308-17. https://doi.org/10.1038/ejhg.2015.26.

7. Cafiero C, Marangi G, Orteschi D, Ali M, Asaro A, Ponzi E, et al. Novel de novo heterozygous loss-of-function variants in MED13L and further delineation of the MED13L haploinsufficiency syndrome. Eur J Hum Genet. 2015:23:1499-504. https://doi.org/10.1038/ejhg.2015.19.

8. van Haelst MM, Monroe GR, Duran K, van Binsbergen E, Breur JM, Giltay JC, et al. Further confirmation of the MED13L haploinsufficiency syndrome. Eur J Hum Genet. 2015;23:135-8. https://doi.org/10.1038/ejhg.2014.69.

9. Yamamoto T. MED13L haploinsufficiency syndrome: a de novo frameshift and recurrent intragenic deletions due to parental mosaicism. Clin Case Rep. 2017;173:1264-9. https://doi.org/10.1002/ajmg.a.38168.

10. Gordon CT, Chopra M. MED13L loss-of-function variants in two patients with syndromic Pierre Robin sequence. Am J Med Genet A. 2018;176:181-6. https://doi.org/10.1002/ajmg.a.38536.

11. Torring PM, Larsen MJ, Brasch-Andersen C, Krogh LN, Kibaek M, Laulund L, et al. Is MED13L-related intellectual disability a recognizable syndrome? Eur J Med Genet. 2019;62:129-36. https://doi.org/10.1016/j.ejmg.2018.06.014.

12. Smol T, Petit F, Piton A, Keren B, Sanlaville D, Afenjar A, et al. MED13Lrelated intellectual disability: involvement of missense variants and delineation of the phenotype. Neurogenetics. 2018;19:93-103. https://doi. org/10.1007/s10048-018-0541-0.

13. Hiatt SM, Bowling KM, Prokop JW, Engel KL, Cochran JN, Bebin EM, et al. Language and cognitive impairment associated with a novel p.Cys63Arg change in the MED13L transcriptional regulator. Hum Genet. 2018;9:83-91. https://doi.org/10.1159/000485638.

14. Asadollahi R, Zweier M, Gogoll L, Schiffmann R, Sticht $H$, Steindl $K$, et al. Genotype-phenotype evaluation of MED13L defects in the light of a nove truncating and a recurrent missense mutation. Eur J Med Genet. 2017;60: 451-64. https://doi.org/10.1016/j.ejmg.2017.06.004.

15. Najmabadi H, Hu H, Garshasbi M, Zemojtel T, Abedini SS, Chen W, et al. Deep sequencing reveals 50 novel genes for recessive cognitive disorders. Nature. 2011;478:57-63. https://doi.org/10.1038/nature10423.

16. Gilissen C, Hehir-Kwa JY, Thung DT, van de Vorst M, van Bon BW, Willemsen $\mathrm{MH}$, et al. Genome sequencing identifies major causes of severe intellectual disability. Nature. 2014;511:344-7. https://doi.org/10.1038/nature13394.

17. Codina-Sola M, Rodriguez-Santiago B, Homs A, Santoyo J, Rigau M, AznarLain $\mathrm{G}$, et al. Integrated analysis of whole-exome sequencing and transcriptome profiling in males with autism spectrum disorders. Mol Autism. 2015;6:21. https://doi.org/10.1186/s13229-015-0017-0.
18. Caro-Llopis A, Rosello M, Orellana C, Oltra S, Monfort S, Mayo S, et al. De novo mutations in genes of mediator complex causing syndromic intellectual disability: mediatorpathy or transcriptomopathy? Pediatr Res. 2016:80:809-15. https://doi.org/10.1038/pr.2016.162.

19. Mullegama SV, Jensik P, Li C, Dorrani N, Kantarci S, Blumberg B, et al. Coupling clinical exome sequencing with functional characterization studies to diagnose a patient with familial Mediterranean fever and MED13L haploinsufficiency syndromes. Clin Case Rep. 2017;5:833-40. https://doi.org/ 10.1002/ccr3.904.

20. Richards S, Aziz N, Bale S, Bick D, Das S, Gastier-Foster J, et al. Standards and guidelines for the interpretation of sequence variants: a joint consensus recommendation of the American College of Medical Genetics and Genomics and the Association for Molecular Pathology. Genet Med. 2015; 17:405-24. https://doi.org/10.1038/gim.2015.30.

\section{Publisher's Note}

Springer Nature remains neutral with regard to jurisdictional claims in published maps and institutional affiliations.
Ready to submit your research? Choose BMC and benefit from:

- fast, convenient online submission

- thorough peer review by experienced researchers in your field

- rapid publication on acceptance

- support for research data, including large and complex data types

- gold Open Access which fosters wider collaboration and increased citations

- maximum visibility for your research: over $100 \mathrm{M}$ website views per year

At $\mathrm{BMC}$, research is always in progress.

Learn more biomedcentral.com/submissions 